\title{
PENGARUH LATIHAN TENDANGAN MENGGUNAKAN BAN KARET TERHADAP HASIL TENDANGAN SABIT PENCAK SILAT
}

\author{
Yustiana Nabila $^{1}$, Marshanda Salsabila Malinda ${ }^{2}$, Yusril Ihza Maulana $^{3}$, Gilang \\ Nuari Panggraita ${ }^{4}$ \\ Universitas Muhammadiyah Pekajangan Pekalongan ${ }^{1,2,3,4}$ \\ nabilayustiana@gmail.com ${ }^{1}$, marshanda259@gmail.com², \\ yusrizihzamaulana2171@gmail.com ${ }^{3}$, panggraita@umpp.ac.id ${ }^{4}$
}

\begin{abstract}
Abstrak
Penelitian ini bertujuan untuk mengetahui pengaruh latihan tendangan menggunakan ban karet terhadap hasil tendangan sabit pencak silat. Metode penelitian ini adalah kuantitaatif dalam bentuk pre eksperimental design. Desain yang di gunakan dalam penelitian ini adalah one group pretest-postest design. Populasi penelitian ini adalah atlet pencak silat putri pra-remaja Kabupaten Pekalongan yang berjumlah 28 orang dengan teknik total sampling. Teknik pengumpulan data menggunakan tes kemampuan tendangan sabit selama 1 menit. Hasil penelitian yang diperoleh yaitu (1) Hasil penelitian pengaruh latihan tendangan dengan ban karet terhadap hasil tendangan sabit pada kaki kiri dengan nilai R-Square sebesar 0,718. Nilai tersebut mengandung arti bahwa latihan berpengaruh terhadap hasil tendangan sabit pada kaki kiri sebesar $71,8 \%$, sedangkan sebesar 28,2\% merupakan hasil keterampilan tendangan sabit kaki kiri yang dipengaruhi oleh variabel lain. (2) Hasil penelitian pengaruh latihan tendangan dengan ban karet terhadap hasil tendangan sabit pada kaki kanan dengan nilai R-Square sebesar 0,771. Nilai tersebut mengandung arti bahwa latihan berpengaruh terhadap hasil tendangan sabit pada kaki kanan sebesar $77,1 \%$, sedangkan sebesar $22,9 \%$ merupakan hasil keterampilan tendangan sabit kaki kanan yang dipengaruhi oleh variabel lain. Dari hasil tersebut dapat artikan bahwa latihan tendangan dengan ban karet berpengaruh terhadap hasil tendangan sabit pencak silat.
\end{abstract}

Kata Kunci: prestasi, latihan, atlet, tendangan sabit, ban karet

\section{THE EFFECT OF KICK TRAINING USING RUBBER TIRES ON THE RESULTS OF THE PENCAK SILAT SICKLE KICK}

\section{Abstract}

This research aims to determine the effect of kick training using a rubber tire on the results of the pencak silat sickle kick. This research method is quantitative in the form of pre experimental design.. The design used in this research was a one group pretest-postest design. The population of this research was 28 female pre-teen martial arts athletes in Pekalongan Regency with total sampling technique. The data collection technique used a sickle kick ability test for 1 minute. The results obtained are (1) The results of the research on the effect of kick training with a rubber tire on the results of a sickle kick on the left foot with an $R$-Square value of 0.718. This value implies that training has an effect on the results of the sickle kick on the left leg by $71.8 \%$, while $28.2 \%$ is the result of the skill of the left foot sickle kick which is influenced by other variables. (2) The results of the research on the effect of kick training with rubber tires on the results of a sickle kick on the right foot with an $R$-Square value of 0.771. This value implies that exercise has an effect on the results of the sickle kick on the right leg by $77.1 \%$, while $22.9 \%$ is the result of the sickle kick skill of the right foot which is influenced by other variables. From these results it can be interpreted that kick practice with rubber tires has an effect on the results of the pencak silat sickle kick.

Correspondence author: Yustiana Nabila, Universitas Muhammadiyah Pekajangan pekalongan, Indonesia. E(c) (i) (2) ustiana@gmail.com

Jurnal HalamanOlahraga Nusantara licensed under a Creative Commons Attribution-ShareAlike 4.0 International License. 
Yustiana Nabila, Marshanda Salsabila Malinda, Yusril Ihza Maulana, Gilang Nuari Panggraita (2021)

Keywords: achievement, training, athlete, sickle kick, rubber tires

\section{PENDAHULUAN}

Olahraga adalah suatu kegiatan yang sistematis dan dapat mendorong, membina, serta mengembangkan potensi jasmani, rohani dan sosial. Olahraga terus berkembang dengan pesat seiring dengan perkembangan modernisasi dan teknologi yang makin canggih dengan adanya berbagai karakteristik dalam bentuk kebutuhan, kesibukan, dan gaya hidup (Lauh et al., 2020). Banyak jenis atau cabang olahraga yang berkembang dan dikenal oleh masyarakat, salah satunya adalah olahraga bela diri yaitu pencak silat. Pencak silat merupakan olahraga yang berasal dari Indonesia. Pencak silat adalah hasil budaya manusia Indonesia untuk membela, mempertahankan, eksistensi (kemandirian) dan integritasnya (manunggal) terhadap lingkungan hidup/alam sekitarnya untuk mencapai keselarasan hidup guna meningkatkan iman dan taqwa (Gristyutawa et al., 2012). Pencak silat menjadi olahraga yang diminati banyak orang, hingga terdapat berbagai klub dan juga padepokan sebagai wadah untu berlatih para pesilat.

Seiring perkembangan zaman pencak silat mulai dipertandingkan dalam kejuaraan baik tingkat daerah, nasional maupun internasional. Kejuaraan tersebut juga dapat dijadikan tolak ukur untuk mengetahui sejauh mana tingkat keberhasilan dari proses pelatihan yang dilakukan dalam suatu klub atau padepokan. Ada beberapa aspek yang perlu dilatih kepada seorang pesilat agar dapat memungkinkan pesilat mencapai prestasi maksimal yaitu latihan fisik, latihan teknik, latihan taktik dan latihan mental (Dewi, 2014)

Pada gerakan pencak silat terdapat teknik gerakan penyerangan dan pertahanan. Pola gerakan serangan dalam pencak silat ada berbagai macam salah satunya adalah tedangan sabit. Tendangan sabit bisa disebut juga dengan tendangan $\mathrm{C}$ karena posisi badan yang meliuk mengikuti ayunan dari tungkai kaki hingga ujung kaki dengan sasaran punggung kaki. Menurut Lubis (2014:35) menyatakan bahwa tendangan busur/sabit adalah tendangan yang lintasannya 
Yustiana Nabila, Marshanda Salsabila Malinda, Yusril Ihza Maulana, Gilang Nuari Panggraita (2021)

PENGARUH LATIHAN TENDANGAN MENGGUNAKAN BAN KARET TERHADAP HASIL TENDANGAN SABIT PENCAK SILAT

OLATRAGA

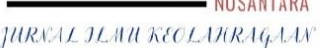

Jendral A. Yani Street Lorong Gotong Royong 9/10 U1 Palembang South Sumatera

email jurnal: jurnalhon@univpgri-palembang.ac.id situs web: http://www.univpgri-palembang.ac.id
Accredited

SINTA 3

setengah lingkaran kedalam, sasaran seluruh bagian tubuh, dengan punggung telapak kaki atau jari telapak kaki. Tendangan sabit dilakukan dengan posisi kudakuda yang kuat dan benar. Dengan ayunan kaki untuk menendang ke arah lawan dan memantulkan punggung kaki ke bagian sasaran. Perkenaan kaki ke sasaran tepat pada bagian punggung kaki. Posisi kedua tangan ditekuk di depan dada untuk menjaga keseimbangan tubuh.

Proses gerakan tendangan sabit dalam olahraga pencak silat dilakukan dengan gerakan pola gerak yang tidak terputus sehingga menjadi suatu rangkaian gerakan yang utuh yaitu mulai dari posisi kuda-kuda, memiringkan badan, mengangkat kaki dengan menendang setinggi lutut dengan sasaran puggung kaki dan meluruskan tungkai dengan gerakan cepat untuk mencapai sasaran pada bagian tubuh lawan. Apabila proses gerakan pencak silat dilakukan dengan tersendat-sendat dan tidak teratur maka dapat mengurangi kelincahan seorang atlet yang melakukan serangan, sehingga sangat mudah untuk ditangkis ataupun ditangkap oleh lawan. Untuk menghasilkan kecepatan bergerak yang cepat diperlukan kecepatan gerak kaki sebagai daya dorong untuk membantu gerakan tungkai pada saat melakukan ayunan (Harliawan \& Darminto, 2020). Seorang atlet pencak silat memerlukan kondisi fisik yang tinggi dalam melakukan tendangan sabit dalam pertandingan.

Terdapat faktor-faktor yang dapat memicu perkembangan prestasi seorang atlet dalam berolahraga. Seperti harus adanya kualitas dalam pelatihan dan pembinaan olahraga sehingga prestasi olahraga dapat berkembang dengan ilmu yang terkait khususnya pada olahraga pencak silat. Some factors can spur the development of achievements in sports, such as quality improvement in training and sports coaching (Pomatahu, 2018). Pelatih harus mampu membuat program latihan yang benar dengan memahami tahap-tahap latihan sehingga mengetahui berapa besar porsi latihan yang dibutuhkan, karena latihan merupakan faktor utama dalam meningkatkan kualitas otot dan kekuatan otot merupakan modal 
Yustiana Nabila, Marshanda Salsabila Malinda, Yusril Ihza Maulana, Gilang Nuari Panggraita (2021)

untuk mempermudah mempelajari teknik dan mencegah terjadinya cedera dan meperoleh prestasi yang maksimal (Kamarudin, 2015). Menurut Pasau dalam Boihaqi (2017) bahwa orang yang mempunyai fisik tinggi dan besar rata-rata akan mempunyai kemampuan fisik seperti kekuatan, kecepatan, daya tahan jantung dan paru-paru, daya tahan otot dan lain-lain lebih baik daripada orang yang bertubuh kecil dan pendek.

Pelaksanaan teknik dasar yang baik dan benar sangat diperlukan dalam pertandingan pencak silat, cara yang harus dilakukan adalah dengan menjalani latihan dengan program latihan yang direncanakan (Pratiwi et al., 2013). Permasalahan kondisi fisik dan kekuatan otot yang lemah membuat tendangan sabit seorang atlet tidak dapat digunakan untuk menyerang dengan optimal. Oleh karena itu dibutuhkan latihan menggunakan metode latihan yang tepat, salah satunya dengan tendangan menggunakan beban dari ban karet yang diikat pada kaki.

\section{METODE}

Metode penelitian ini adalah kuantitaatif dalam bentuk pre eksperimental designe. Desain yang di gunakan dalam penelitian ini adalah one group pretestpostest design, yaitu desain penelitian yang terdapat pretest sebelum diberi perlakuan dan posttest setelah diberi perlakuan. Dengan demikian dapat diketahui lebih akurat, karena dapat membandingkan dengan diadakan sebelum diberi perlakuan (Sugiyono dalam Prasetyo, 2015). Populasi penelitian ini adalah atlet pencak silat putri pra-remaja Kabupaten Pekalongan yang berjumlah 28 orang. Dalam penelitian ini menggunakan teknik total sampling, artinya seluruh atlet putri menjadi sampel yang berjumlah 28 orang.Penelitian ini dilakukan di Padepokan perguruan pencak silat kera putih Pekalongan

Data yang digunakan dalam penelitian ini adalah data tendangan sabit. Teknik pengumpulan data menggunakan tes kemampuan tendangan sabit selama 1 
Yustiana Nabila, Marshanda Salsabila Malinda, Yusril Ihza Maulana, Gilang Nuari Panggraita (2021)

PENGARUH LATIHAN TENDANGAN MENGGUNAKAN BAN KARET TERHADAP HASIL TENDANGAN SABIT PENCAK SILAT

\section{OLATRAGA}

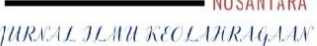

Jendral A. Yani Street Lorong Gotong Royong 9/10 U1 Palembang South Sumatera

email jurnal: jurnalhon@univpgri-palembang.ac.ic situs web: http://www.univpgri-palembang.ac.ic
Accredited

SINTA 3

menit. Tendangan dilakukan sebanyak 2 kali yaitu tendangan kaki kanan dan kaki kiri. Berikut ini adalah norma kemampuan tendangan sabit:

Tabel 1. Norma tes kemampuan tendangan sabit

\begin{tabular}{lcc}
\multicolumn{1}{c}{ Kategori } & Putri & Putra \\
\hline Baik Sekali & $>24$ & $>25$ \\
Baik & $19-23$ & $20-24$ \\
Cukup & $16-18$ & $17-19$ \\
Kurang & $13-15$ & $15-16$ \\
Kurang Sekali & $<12$ & $<14$
\end{tabular}

Analisis data yang digunakan adalah uji normalitas, uji homogenitas dan analisis regresi menggunakan uji-t.

\section{HASIL DAN PEMBAHASAN}

Pada penelitian ini menggunaan jenis penelitian quasi eksperimental desinge dengan bentuk pre test post test control design dan menggunakan metode kuantitatif Sugiyono (2018:120). Penelitian ini bertujuan untuk mengetahui pengaruh tendangan menggunakan ban karet terhadap tendangan sabit atlet pencak silat putri pra-remaja. Untuk mengetahu hal tersebut dilakukan Pre-test terlebih dahulu, selanjutnya atlet diberikan perlakuan berupa latihan tendangan menggunakan ban karet yang dilaksanakan sebanyak 16 kali pertemuan dengan 3 kali repetisi per 1 menit, dalam 16 kali pertemuan terhitung pada pertemuan awal pretest (latihan awal sebelum di lakukan metode latihan) dan 14 pertemuan selama melakukan metode latihan, serta pertemuan terakhir sebagai posttest (test akhir setelah melakukan metode latihan).

Tabel 2. Hasil Pre-Test dan Post-Test Tendangan Sabit

\begin{tabular}{cccccc}
\hline \multirow{2}{*}{ Kategori } & \multirow{2}{*}{$\begin{array}{c}\text { Rentang } \\
\text { Nilai }\end{array}$} & $\begin{array}{c}\text { Pre test } \\
\text { Kaki } \\
\text { kanan }\end{array}$ & $\begin{array}{c}\text { Kaki } \\
\text { kiri }\end{array}$ & $\begin{array}{c}\text { Kaki } \\
\text { kanan }\end{array}$ & $\begin{array}{c}\text { Kaki } \\
\text { kiri }\end{array}$ \\
\hline Baik Sekali & $>24$ & & & & 5 \\
Baik & $19-23$ & & 3 & 16 & 19 \\
Cukup & $16-18$ & 3 & 15 & 8 & 4 \\
Kurang & $13-15$ & 19 & 9 & 4 &
\end{tabular}


Yustiana Nabila, Marshanda Salsabila Malinda, Yusril Ihza Maulana, Gilang Nuari

$\begin{array}{cccccc}\text { Kurang sekali } & <12 & 6 & 1 & & \\ \text { Total } & & 28 & 28 & 28 & 28\end{array}$

Sebelum melakukan analisis data, dilakukan uji prasyarat analisis yaitu dengan uji normalitas dan uji homogenitas.

Tabel 3. Hasil Uji Normalitas

\begin{tabular}{llrrrrrr}
\hline & & \multicolumn{3}{c}{ Kolmogorov-Smirnov $^{\mathrm{a}}$} & \multicolumn{3}{c}{ Shapiro-Wilk } \\
Kelas & & Statistic & \multicolumn{1}{c}{ df } & \multicolumn{1}{c}{ Sig. } & Statistic & \multicolumn{1}{c}{ Df } & \multicolumn{1}{c}{ Sig. } \\
\hline Hasil & Pre Kanan & .156 & 28 & .080 & .941 & 28 & .119 \\
& Post Kanan & .196 & 28 & .007 & .936 & 28 & .086 \\
& Pre Kiri & .138 & 28 & .185 & .967 & 28 & .495 \\
& Post Kiri & .110 & 28 & $.200^{*}$ & .961 & 28 & .376
\end{tabular}

Berdasarkan tabel 3 dapat dilihat bahwa nilai signifikansi hsail pre-test dan post-test kaki kiri maupuan kanan lebih besar dari 0,05. Sehingga, dapat disimpulkan bahwa data berdistribusi normal.

Tabel 4. Hasil Uji Homogenitas

\begin{tabular}{rrrr}
$\begin{array}{c}\text { Levene } \\
\text { Statistic }\end{array}$ & df1 & \multicolumn{1}{c}{ df2 } & Sig. \\
\hline 1.948 & 3 & 108 & .126 \\
\hline
\end{tabular}

Hasil tabel diatas menunjukkan bahwa nilai signifikansi (sig.) sebesar 0,126. Nilai Sig, 0,126>0,05, maka bisa diambil keputusan bahwa varians data tersebut bersifat sama atau homogen.

Setelah dilakukan uji normalitas dan homogenitas, selanjutnya dilakukan pengujian hipotesis menggunakan uji analisis regresi. Penelitian ini memiliki satu hipotesis yaitu terdapat pengaruh latihan tendangan dengan ban karet terhadap hasil tendangan sabit. Data yang diperoleh berupa hasil tendangan sabit kaki kiri dan kaki kanan. Maka dilakukan uji hipotesis terhadap masing-masing kaki.

Tabel 5. Uji Hipotesis R-square Tendangan dengan Ban Karet terhadap hasil tendangan sabit kaki kiri

\begin{tabular}{|c|c|c|c|c|}
\hline Model & $\mathrm{R}$ & $\begin{array}{c}\mathrm{R} \\
\text { Square }\end{array}$ & $\begin{array}{l}\text { Adjusted R } \\
\text { Square }\end{array}$ & $\begin{array}{l}\text { Std. Error of } \\
\text { the Estimate }\end{array}$ \\
\hline 1 &, $718^{\mathrm{a}}$ & .515 & .506 & 2.241 \\
\hline
\end{tabular}


Yustiana Nabila, Marshanda Salsabila Malinda, Yusril Ihza Maulana, Gilang Nuari Panggraita (2021)

PENGARUH LATIHAN TENDANGAN MENGGUNAKAN BAN KARET TERHADAP HASIL TENDANGAN SABIT PENCAK SILAT

\section{OLAHRAGA}

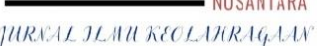

Jendral A. Yani Street Lorong Gotong Royong 9/10 U1 Palembang South Sumatera

email jurnal: jurnalhon@univpgri-palembang.ac.ic situs web: http://www.univpgri-palembang.ac.ic
Accredited

SINTA 3

Hasil penelitian pengaruh latihan tendangan dengan ban karet terhadap hasil tendangan sabit pada kaki kiri dengan nilai R-Square sebesar 0,718. Nilai tersebut mengandung arti bahwa latihan berpengaruh terhadap hasil tendangan sabit pada kaki kiri sebesar 71,8\%, sedangkan sebesar 28,2\% merupakan hasil keterampilan tendangan sabit kaki kiri yang dipengaruhi oleh variabel lain.

Tabel 6. Uji Hipotesis F Hitiing Tendangan dengan Ban Karet terhadap hasil tendangan sabit kaki kiri.

\begin{tabular}{|c|c|c|c|c|c|c|}
\hline \multicolumn{2}{|c|}{ Model } & $\begin{array}{l}\text { Sum of } \\
\text { Squares }\end{array}$ & $\mathrm{df}$ & $\begin{array}{l}\text { Mean } \\
\text { Square }\end{array}$ & \multirow{2}{*}{$\frac{F}{57.368}$} & \multirow{2}{*}{$\begin{array}{l}\text { Sig. } \\
, 011^{\mathrm{b}}\end{array}$} \\
\hline 1 & Regression & 288.018 & 1 & 288.018 & & \\
\hline & Residual & 271.107 & 54 & 5.021 & & \\
\hline & Total & 559.125 & 55 & & & \\
\hline
\end{tabular}

Hasil perhitungan nilai $\mathrm{F}$ hitung menunjukkan sebesar 57,368 dengan nilai signifkansi sebesar 0,011 , dimana nilai sigkansi $0,011<0,05$. Ini menunjukkan bahwa terdapat pengaruh latihan tendangan dengan ban karet terhadap hasil tendangan sabit pada kaki kiri.

Tabel 7. Uji Hipotesis R-square Tendangan dengan Ban Karet terhadap hasil tendangan sabit kaki kanan

\begin{tabular}{llrrr} 
Model & $\mathrm{R}$ & $\begin{array}{c}\mathrm{R} \\
\text { Square }\end{array}$ & $\begin{array}{c}\text { Adjusted R } \\
\text { Square }\end{array}$ & $\begin{array}{r}\text { Std. Error of } \\
\text { the Estimate }\end{array}$ \\
\hline 1 &, $771^{\mathrm{a}}$ & .595 & .587 & 1.922
\end{tabular}

Hasil penelitian pengaruh latihan tendangan dengan ban karet terhadap hasil tendangan sabit pada kaki kanan dengan nilai R-Square sebesar 0,771. Nilai tersebut mengandung arti bahwa latihan berpengaruh terhadap hasil tendangan sabit pada kaki kanan sebesar 77,1\%, sedangkan sebesar 22,9\% merupakan hasil keterampilan tendangan sabit kaki kanan yang dipengaruhi oleh variabel lain.

Tabel 8. Uji Hipotesis F Hitung Tendangan dengan Ban Karet terhadap hasil tendangan sabit kaki kanan.

\begin{tabular}{|c|c|c|c|c|}
\hline Model & $\begin{array}{l}\text { Sum of } \\
\text { Squares }\end{array}$ & $\mathrm{df}$ & $\begin{array}{l}\text { Mean } \\
\text { Square }\end{array}$ & F \\
\hline
\end{tabular}


Yustiana Nabila, Marshanda Salsabila Malinda, Yusril Ihza Maulana, Gilang Nuari Panggraita (2021)

PENGARUH LATIHAN TENDANGAN MENGGUNAKAN BAN KARET TERHADAP HASIL TENDANGAN SABIT PENCAK SILAT

OLAHRAGA

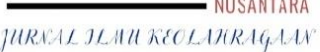

Jendral A. Yani Street Lorong Gotong Royong 9/10 U1u Palembang South Sumatera

email jurnal: jurnalhon@univpgri-palembang.ac.id situs web: http://www.univpgri-palembang.ac.id
Accredited

SINTA 3

\begin{tabular}{llrrrrr}
\hline 1 & Regression & 292.571 & 1 & 292.571 & 79.221 &, $016^{\mathrm{b}}$ \\
& Residual & 199.429 & 54 & 3.693 & & \\
Total & 492.000 & 55 & & & \\
\hline
\end{tabular}

Hasil perhitungan nilai $\mathrm{F}$ hitung menunjukkan sebesar 79,221 dengan nilai signifkansi sebesar 0,016, dimana nilai sigkansi $0,016<0,05$. Ini menunjukkan bahwa terdapat pengaruh latihan tendangan dengan ban karet terhadap hasil tendangan sabit pada kaki kanan.

\section{PEMBAHASAN}

Pada dasarnya pembebanan ban karet dalam tendangan sabit melibatkan beberapa unsur yang tentunya untuk menciptakan dan mencapai tujuan atlet yang maksimal. Dalam metode pembebanan tendangan sabit menggunakan ban karet seorang atlet harus juga memiliki keterampilan lebih dan memiliki fisik dan teknik yang cukup memadai. Mulai dari teknik yang benar, daya tahan, dan kekuatan. Selanjutnya Harsono dalam Manullang (2018) mengemukakan bahwa, perkembangan kondisi fisik yang menyeluruh amatlah penting karena tanpa kondisi fisik yang baik atlet tidak akan dapat mengikuti latihan- latihan dengan sempurna.

Latihan yang sistematis dapat dilakukan dengan menggunakan beban untuk menambah kekuatan otot. Hal ini juga berfungsi untuk mencapai tujuan yaitu perbaikan kekuatan kondisi fisik, Kesehatan dan pencapaian prestasi dalam suatu cabang olahraga khususnya pencak silat. Komponen kondisi fisik dalam olahraga beladiri pencak silat diantaranya daya tahan (endurance). Daya tahan ini berkaitang dengan waktu pertandingan yang dilakukan dalam satu kali tanding. Seorang pesilat harus bertanding dalam waktu dua menit kali tiga babak dengan teknik yang sempurna untuk bisa memenangkan pertandingan. Selain daya tahan, komponen kondisi fisik lainnya yang tidak kalah penting dalam pertandingan silat adalah kecepatan (speed), kekuatan (strength), daya ledak (power), kelentukan (flexibility) dan kelincahan (agility). Komponen kondisi fisik ini berguna untuk 
Yustiana Nabila, Marshanda Salsabila Malinda, Yusril Ihza Maulana, Gilang Nuari Panggraita (2021)

PENGARUH LATIHAN TENDANGAN MENGGUNAKAN BAN KARET TERHADAP HASIL TENDANGAN SABIT PENCAK SILAT

OLATRAGA

JURAAL JLHUKCOLIMRAGIAH
Jendral A. Yani Street Lorong Gotong Royong 9/10 U1 Palembang South Sumatera

email jurnal: jurnalhon@univpgri-palembang.ac.id situs web: http://www.univpgri-palembang.ac.id
Accredited

SINTA 3

bergerak keseluruh penjuru gelanggang untuk menyerang dalam gerakan memukul, menendang, menangkis dan mengelak (Kamarudin, 2015)

Menurut (Abdurahman et al., 2014) menyatakan bahwa tendangan busur atau tendangan sabit merupakan tendangan yang paling dominan digunakan dalam bertarung khususnya pada kategori tanding karena tendangan ini sangat praktis dan efisien digunakan dalam menyerang maupun belaan. Tendangan busur adalah tendangan yang sering dilakukan saat pertandingan karena tingkat efisiensi yang mudah untuk melakukan serangan atau belaan. Para pesilat serinng kali menggunakan tendangan sabit dikarenakan tendangan ini sedikit sulit diprediksi kecepatan tendangannya, walaupun tendangan sabit merupakan tendangan yang paling mudah ditangkap tetapi jika tendangan ini dilakukan dengan teknik yang benar disertai power yang kuat maka tendangan dapat dijadikan ujung tombak untuk melawan.

Keefektifan tendangan sabit dalam pertandingan diperkuat dengan pernyataan Kiswanto dalam Maulana \& Wijaya (2018) bahwa tendangan sabit adalah tendangan yang paling mudah di lakukan, yaitu membentuk sabit, setengah lingkaran atau seperti huruf "C" pergerakan dilakukan dari pangkal paha kemudian hentakan bagian lutut hingga ujung kaki dan perkenaanya bagian punggung kaki ke bagian dada atau perut lawan. Berdasarkan kutipan tersebut tendangan sabit bisa disebut juga sebagi tendangan "C", dimana pergerakan tendangan sabit dimulai dari pangkal paha yang dinaikkan membentuk lengkungan atau huruf "C" dengan perkenaan punggung kaki.

Bentuk gerakan tendangan sabit yang melengkung dengan perkenaan punggung kaki memerlukan keterampilan atlet untuk dapat melakukan dengan benar sehingga dapat menyerang lawan tanding. Gerakan sabit juga menggunakan liukan badan agar tendangan sabit diarahkan pada bagian perut dan dada lawan. Peningkatan semua aspek kondisi fisik terutama power pada otot tungkai menjadi pusat dari latihan tendangan sabit. 
Yustiana Nabila, Marshanda Salsabila Malinda, Yusril Ihza Maulana, Gilang Nuari Panggraita (2021)

Pada proses latihan upaya untuk meningkatkan prestasi seorang atlet tidak ada cara lain selain berlatih, dengan begitu setiap atlet harus belatih untuk mencapai tujuan yang maksimal. Tujuan utama latihan adalah untuk mengembangkan keterampilan dan performa atlet, atlet dibimbing oleh pelatih agar terdapat penambahan beban di setiap program latihannya untuk mencapai keterampilan atlet seperti yang diharapkan.

Berdasarkan hasil penelitian latihan menggunakan ban karet dapat menjadi salah satu latihan beban yang efektif dalam meningkatkan hasil tendangan sabit pencak silat. Hal ini dikarenakan ban karet memiliki sifat elastisitas dan gaya pegas. Sifat tersebut juga dapat digunakan dalam suatu proses latihan ketahanan. Melalui pemanfaatan gaya tarik-menarik oleh karet dapat memicu otot yang berkontaksi. Menurut Martens dalam Pranata (2019) menyatakan bahwa kecepatan tendangan dapat ditingkatkan menggunakan latihan beban yaitu dengan latihan gaya pegas sifat elastisitas karet ban dalam. Tahanan karet merupakan alat bantu latihan yang dapat digunakan untuk meningkatkan kecepatan tendangan karena latihan tahanan dapat meningkatkan kecepatan.

\section{KESIMPULAN}

Berdasarkan hasil pengujian hipotesis dalam penelitian ini dapat disimpulkan bahwa terdapat pengaruh latihan pembebanan ban karet pada kaki baik kaki kananan maupun kaki kiri pada hasil tendangan sabit. Latihan menggunakan ban karet dapat mempercepat tendangan sabit dengan latihan yang dilakukan dengan cara yang sistematis dan pembebanan yang dipakai dapat menambah kekuatan otot. Gaya pegas dan sifat elastisitas karet ban dalam menjadi beban yang digunakan dalam melatih kecepatan tendangan. Berbagai penelitian menunjukan bahaw latihan merupakan faktor utama dalam meningkatkan kualitas otot dan kekuatan otot merupakan modal untuk mempermudah mempelajari teknik dan mencegah terjadinya cedera dan meperoleh prestasi yang maksimal. Hal ini berfungsi untuk mencapai tujuan untuk 
Yustiana Nabila, Marshanda Salsabila Malinda, Yusril Ihza Maulana, Gilang Nuari Panggraita (2021)

PENGARUH LATIHAN TENDANGAN MENGGUNAKAN BAN KARET TERHADAP HASIL TENDANGAN SABIT PENCAK SILAT

HALAMAN Jendral A. Yani Street Lorong Gotong Royong 9/10 U1u

memperbaiki suatu kondisi fisik, kesehatan, kekuatan, prestasi, dalam cabang olahraga khususnya pencak silat

\section{UCAPAN TERIMAKASIH}

Terimakasih kepada LPPM dan civitas akademik UMPP yang telah memberikan dukungan materi serta motivasi sehingga kegiatan penelitian bisa terlaksana tanpa adanya suatu hambatan apapun. Terimakasih kepada KONI Kabupaten Pekalongan yang telah memberi kesempatan pada peneliti dan memfasilitasi tempat penelitian sehingga peneliti dapat mengetahui hasil dari penelitian.

\section{DAFTAR PUSTAKA}

Abdurahman, R. M., Simanjuntak, V., \& Purnomo, E. (2014). Keterampilan Gerak Dasar Tendangan Sabit Di Perguruan Pencak Silat Kijang Berantai Kota Pontianak. Jurnal Pendidikan Dan Pembelajaran, 3(6).

Boihaqi. (2017). ANALISIS KONDISI FISIK ATLET SEPAKBOLA SMA NEGERI 4 BANDA ACEH. Universitas Serambi Mekkah ISSN 2355-0058, 4, 121-135. https://doi.org/10.1088/1751-8113/44/8/085201

Dewi, A. K. (2014). Kontribusi kelincahan dan kecepatan terhadap tendangan sabit pada atlet pencak silat putra usia 12-14 tahun. Jurnal Ilmu Kesahatan Universitas Negeri Surabaya, 2 (2), 158-163.

Gristyutawa, A. D., Purwono, E. P., \& Widodo, A. (2012). Persepsi Pelajar Terhadap Pencak Silat Sebagai Warisan Budaya Bangsa Sekota Semarang Tahun 2012. ACTIVE: Journal of Physical Education, Sport, Health and Recreation, 1(3). https://doi.org/10.15294/active.v1i3.443

Harliawan, M., \& Darminto, A. O. (2020). KONTRIBUSI KECEPATAN BERGERAK, REAKSI KAKI, DAN DAYA LEDAK TUNGKAI TERHADAP KEMAMPUAN LARI 100 METER PADA SISWA SMK NEGERI 2 MAKASSAR. 3(Ii), 145-156.

Kamarudin. (2015). Pengaruh Metode Berbeban Terhadap Kecepatan Tendangan Sabit Pada Atlet Pencak Silat Unit Kegiatan Mahasiswa Universitas Islam Riau. Primary: Jurnal Pendidikan Guru Sekolah Dasar, 3(2), 82. https://doi.org/10.33578/jpfkip.v3i2.2498

Lauh, W. D. A., Fallo, I. S., \& Dewi, U. (2020). Pengembangan Model Permainan Pembelajaran Renang Untuk Mahasiswa. Halaman Olahraga Nusantara $\begin{array}{llll}\text { (Jurnal Ilmu } & \text { Keolahragaan), } & 3(2),\end{array}$ 
https://doi.org/10.31851/hon.v3i2.4476

Lubis, J. (2014). Pencak Silat. Jakarta : PT Raja Grafindo Persada

Manullang, J. G. (2018). Pengaruh Latihan Split Squat Jump Dan Latihan Maegeri Dari Posisi Jongkok Terhadap Kecepatan Tendangan Maegeri Chudan Pada Atlet Karateka Putera Sabuk Hijau Perguruan Wadokai Dojo Ketsu 1 Palembang. Halaman Olahraga Nusantara (Jurnal Ilmu Keolahragaan), 1(2), 133-262.

Maulana, A., \& Wijaya, M. R. A. (2018). Pengaruh Latihan Terhadap Kecepatan Tendangan Sabit Pesilat Putri Ekstrakurikuler Pencak Silat Smp Negeri 2 Gunung Guruh Kabupaten Sukabumi 2017 / 2018. Jurnal Repository Ummi, $142-147$.

Pomatahu, A. (2018). Trends in Sport Sciences. Sport in Sport Sciences, 2, 43.

Pranata, L. D. (2019). KINESTETIK: Jurnal Ilmiah Pendidikan Jasmani, 3 (1) 2019 ISSN:2477-331X. 3(1).

Prasetyo, H. D. (2015). Perbedaan Pengaruh Latihan Shuttle Run Dan Zig-Zag Run Terhadap Peningkatan Keterampilan Dribbling Siswa Ekstrakurikuler Sepakbola Sma Negeri 1 Banguntapan. Thesis. Fakultas Ilmu Keolahragaan:UNY

Pratiwi, R. A., Purnomo, E., \& Haetami, M. (2013). Pengaruh Latihan Plyometrik Terhadap Kecepatan Tendangan T Pencak Silat. FKIP UNTAN Pontianak, 18.

Sugiyono. (2018). Metode Penelitian Kuantitatif, Kualitatif dan $R \& D$ Bandung:Alfabeta 